\title{
A Arte da improvisação musical ao teclado no Renascimento italiano: a didática do contraponto segundo Girolamo Diruta (1610) ${ }^{1}$
}

\author{
The Art of Musical Improvisation on The Keyboard during the Italian \\ Renaissance: Counterpoint Teaching According to Girolamo Diruta (1610)
}

\section{Delphim Rezende Porto}

Universidade de São Paulo, São Paulo, SP.

delphim@usp.br

Resumo: Parte fundamental do exercício profissional do tecladista no Renascimento, a improvisação musical é o relevante tema do livro II da segunda parte do tratado Il Transilvano (1610). Única obra publicada pelo organista Girolamo Diruta (1554?1610?), o Transilvano expõe em 'Diálogo' as preceptivas da arte da música de seu tempo e é Monumentum da memória dos principais mestres atuantes na Sereníssima República de Veneza no século XVI - Adriano Willaert, Gioseffo Zarlino e Claudio Merulo. Padre da ordem franciscana e reconhecido organista das igrejas catedrais de Chioggia e Gobbio, Diruta registra por extenso a fortuna do ensino da Fantasia ao teclado como ápice e fim de um profundo estudo do Contraponto e seus artifícios. A partir da exposição desses preceitos, o presente artigo pretende contextualizar a livre - mas "correta" - manipulação dos sons segundo aquela técnica histórica e oferecer ao seu leitor um panorama da didática da música renascentista.

Palavras-chave: contraponto renascimentista; improvisação em teclados antigos; Girolamo Diruta.

Abstract: Fundamental part of the professional keyboardist practice in the Renaissance, musical improvisation is the relevant subject of Book II of the treatise Il Transilvano (1610). Published by Girolamo Diruta (? 1554 -1610), the Transylvanian exposes in 'Dialogue' the precepts of the art of music of his time and is Monumentum of its masters - Adriano Willaert, Gioseffo Zarlino and Claudio Merulo - active composers in the Most Serene Republic of Venice in sixteenth-century. Priest of the Franciscan order and renowned organist of the cathedral churches of Chioggia and Gobbio, Diruta writes down the fortune of the Fantasia on the keyboard as the higher development of the study of Counterpoint. Based on the exposition of these principles, this article aims

1 Pesquisa apoiada pela FAPESP (processo 2014/26766-2). 
PORTO, Delphim Rezende. A Arte da improvisação musical ao teclado no Renascimento italiano: a didática do contraponto segundo Girolamo Diruta (1610). Per Musi. Ed. por Fausto Borém, Eduardo Rosse e Débora Borburema. Belo Horizonte: UFMG, n.33, p.79-96.

to contextualize the free - but "right" - manipulation of sounds according to that historical technique and offer an overview of Renaissance's musical techniques.

Keywords: Renaissance counterpoint; improvisation on early keyboards; Girolamo Diruta.

Data de recebimento: 03/12/2015

Data de aprovação final: 10/04/2016

\section{1 - A fonte do artifício: o tratado Il Transilvano}

Publicado em dois volumes - o primeiro em 1593 e o segundo em 1610 - sob a imprensa veneziana da famosa casa editorial Vicenti, $O$ Transilvano é obra do organista franciscano Frei Girolamo Diruta, herdeiro da tradição dos principais mestres musicais atuantes na sereníssima Veneza no século XVI - Adriano Willaert, Gioseffo Zarlino, Costanzo Porta, Andrea e Giovanni Gabrieli e Claudio Merulo. Um dos escritos italianos mais amplos sobre a prática musical para instrumentos de teclado do período, este tratado é também importante registro da didática musical. Endereçado aos interessados na prática tecladística, especialmente ao órgão de tubos, este "diálogo sobre o verdadeiro modo de tocar órgão e instrumentos de teclado", apresenta os assuntos da música prática italiana através da emulação dialogal entre um nobre transilvano e Pe. Diruta. Para além dos assuntos técnicos inerentes ao órgão e ao teclado, Il Transilvano fundamenta-se por excelência como um detalhado registro da formação do músico prático, ou seja, do eloquente artífice da música. A escolha e a disposição dos assuntos a serem explicados é também índice para este argumento.

O primeiro volume do tratado é dedicado aos mais basilares assuntos da arte, como a leitura musical, a maneira correta de sentar-se frente ao instrumento, a postura adequada e elegante do organista, a escolha dos dedos, enfim, a preparação não só técnica, mas, também, do modo de agir exterior do instrumentista. 0 segundo volume, mais técnico, apresenta-se dividido em quatro livros e a ordem com que são dispostas as ementas de cada livro representam muito bem as virtudes esperadas do tecladista: primeiramente é necessário aprender a ler bem as diversas formas de partituras ao 
PORTO, Delphim Rezende. A Arte da improvisação musical ao teclado no Renascimento italiano: a didática do contraponto segundo Girolamo Diruta (1610). Per Musi. Ed. por Fausto Borém, Eduardo Rosse e Débora Borburema. Belo Horizonte: UFMG, n.33, p.79-96.

órgão e também a escrever e transcrever música corretamente para esse fim (primeiro livro); depois é preciso que o organista aprenda a modular os sons corretamente através da técnica do contraponto (segundo livro) e submetê-los a um modo ou tom que, por sua natureza, é capaz de representar ou descrever um determinado efeito ou afeto (terceiro livro); por último, deverá desenvolver a capacidade de acompanhar um coral e dialogar com este, bem como escolher os timbres do órgão de acordo com os modos e os efeitos decorosos ao momento litúrgico e ao assunto tratado (quarto livro).

O sucesso da publicação de ambos os volumes é referido como fortuna entre diversos autores contemporâneos a Diruta, como Adriano Banchieri (1568-1634) e Ludovico Zacconi (1555-1627) que o citam em suas obras. Banchieri declara os preceitos do Il Transilvano como os mais detalhados acerca da doutrina do dedilhado expressivo tecladístico do período ao tratar sobre a questão no L'Organo Suonarino $(1605$, fl.A2). No volume II do Prattica di Musica - uma das mais completas referências renascentistas para os assuntos do contraponto - Ludovico Zacconi (1622, p.57-128) utiliza prestigiosamente muitos dos exemplos publicados por Diruta em seu tratado.

É, contudo, no segundo livro do volume II do Transilvano, ao qual nos deteremos, que o autor desenvolve o assunto da improvisação ao teclado. Como se haveria de esperar, para Diruta, improviso ou fantasia é o mesmo que contraponto alla mente ao teclado: uma livre sobreposição de duas ou mais melodias sem, a princípio, nenhum artifício particular obrigatório (obbligo), que, porém, segue as mesmas regras fundamentais do contraponto escrito. Para este fim, nosso tratadista colige uma série de juízos doxásticos, basicamente relacionados ao entendimento da natureza dos sons consonantes e dissonantes e o movimento possível entre eles nas auctoritates para este tema - Gioseffo Zarlino (1517-1590), Henricus Glareanus (1488-1563) e outros. A improvisação ao instrumento, neste sentido, torna patente - como ápice e fim - a preparação do discípulo para a manipulação criativa e regrada dos diversos artifícios do contraponto sem a necessidade de deitá-los primeiro ao papel. Nas palavras de DIRUTA no início do II livro da segunda parte do Transilvano (1610, p.215)²: “[...] eu

\footnotetext{
${ }^{2} \mathrm{~A}$ correspondência de páginas do tratado Il Transilvano citadas neste artigo se refere à paginação da Dissertação de Mestrado de Delphim Rezende Porto que o traduz à língua portuguesa.
} 
PORTO, Delphim Rezende. A Arte da improvisação musical ao teclado no Renascimento italiano: a didática do contraponto segundo Girolamo Diruta (1610). Per Musi. Ed. por Fausto Borém, Eduardo Rosse e Débora Borburema. Belo Horizonte: UFMG, n.33, p.79-96.

também pouco dormi pensando no modo que deveria proceder para ensinar-vos facilmente a Arte do Contraponto ao nosso instrumento - porque este deve ser o nosso papel pautado (grifos nossos) [...]"3.

Essa habilidade, contudo, vai gradualmente sendo preparada através de um método que primeiro educa o ouvido do discípulo para bem julgar aquilo que venha a escrever. Não é de pouca importância a consideração que aqueles antigos autores tinham com o contraponto, uma vez que, é unânime a discussão, ao lado do aprendizado dos modos ou tons, dos preceitos que o regulam em todos os manuais de música - inclusive naqueles que se dedicam, aparentemente, somente aos instrumentos.

\section{2 - A ciência da manipulação dos sons}

Na cultura do Renascimento, aprender contraponto, segundo ZACCONI (1622, p.5) equivale a aprender música - pois o seu processo pedagógico, desde o primeiro exercício, visa treinar o arbítrio e o ouvido do aprendiz da arte com regras precisas e graduais sobre o que é correto - portanto, bom - na manipulação do som. G. Maria ARTUSI (1585, p.7) declara que, no âmbito da música especulativa, de todos os sons que existem no universo, alguns são de interesse do músico e para este propósito foram ordenados para que pudessem ser manipulados segundo uma regra. Estes sons são de dois tipos distintos: consonâncias e dissonâncias. Matematicamente consideradas na natureza, as consonâncias foram percebidas e divididas também em dois tipos: perfeitas e imperfeitas. 0 uníssono, a quinta e a oitava, são aqueles intervalos que podem ser demonstrados, para o autor, como consonâncias absolutas e, a terça e a sexta, como consonâncias menores, imperfeitas. Embora nos temperamentos mesotônicos seja possível demonstrar essa relação de maneira diversa, essa adjetivação intervalar obedece ao argumento matemático (especulativo) da música teórica e é aceito como verdadeiro àqueles compositores - como argumenta ZARLINO (1558, p.86-97) na segunda parte das Instituições Harmônicas, especialmente nos

\footnotetext{
3 “...Et io ancora hò poco dormito, pensando qual modo douesse tenere nell'informarui facilmente dell'arte del Contrapunto sopra il nostro instrumento, perche questo hà da essere la nostra cartela..."
} 
PORTO, Delphim Rezende. A Arte da improvisação musical ao teclado no Renascimento italiano: a didática do contraponto segundo Girolamo Diruta (1610). Per Musi. Ed. por Fausto Borém, Eduardo Rosse e Débora Borburema. Belo Horizonte: UFMG, n.33, p.79-96.

capítulos 17 a 26 . Na língua antiga italiana os principais intervalos musicais referidos por DIRUTA (1610) são os seguintes:

\begin{tabular}{|c|c|}
\hline Unísono & Uníssono \\
\hline Semituono & Segunda menor \\
\hline Tuono & Segunda maior \\
\hline Semidittono & Terça menor \\
\hline Dittono & Terça maior \\
\hline Diatesseron & Quarta \\
\hline Diapente & Quinta \\
\hline Esachordo maggiore & Sexta maior \\
\hline Esachordo minore & Sexta menor \\
\hline Ettachordo minore & Sétima menor \\
\hline Ettachordo maggiore & Sétima maior \\
\hline Diapason & Oitava \\
\hline
\end{tabular}

Figura 1: Tabela com os antigos intervalos musicais e seus correspondentes hodiernos.

Além da habitual classificação acima exposta, os intervalos musicais poderiam ser ordenados entre si segundo diversas espécies. A espécie de um intervalo indica ordinariamente a distribuição e a quantidade de ocorrências das sílabas de solmização 4 mi-fa entre as notas que compõem o mesmo. Por exemplo, um intervalo de sexta maior é assim chamado porque ao longo da escala que intrinsecamente contém este intervalo há a ocorrência de apenas um $m i-f a^{5}$, enquanto que, na sexta menor, esta sílaba ocorre duas vezes: De Dó a Lá: ut-re-mi-fa-sol-la; de Ré a Sib: re-mi-fa-re-mi-fa. 0 mesmo ocorre em todos os outros intervalos. Na Terça, por exemplo, Dó-Mi: ut-re-mi, não há ocorrência do $m i-f a$, portanto, é chamada maior, enquanto que na terça Ré-Fá: re-mi$\boldsymbol{f a}$, temos o referido semitom - que a faz terça menor. Além da quantidade do referido semitom, a sua distribuição também interessa, principalmente para a escala modal assunto desenvolvido no terceiro livro da segunda parte do Transilvano. Ainda:

\footnotetext{
${ }^{4}$ Descreve Antonio Exímeno na obra Del origen y reglas de la música $(1774$, p.22) a questão da solmização e do solfejo - duas práticas de leitura musical que coexistiam em seu tempo: "...querendo melhorar o sistema de Guido d"Arezzo, os ultramontanos acrescentaram ao solfejo a sílaba SI, para distinguir e entoar a sétima corda (nota), em cujo lugar, no solfejo de Guido se tornava a repetir alguma das sílabas já entoadas. Assim, os franceses quase abandonaram os nomes de C-sol-fa-ut, D-la-sol-re, etc, substituindo em seu lugar as sílabas $U t, R e, M i, F a, S o l, L a, S i$; de maneira que o que significa na boca de um francês a corda Sol, na de um italiano ou espanhol significa $G$-sol-re-ut. Na Itália é muito frequente o método de solfejar com as sete referidas sílabas, mudando unicamente o Ut em Dó...".

${ }^{5}$ Considere, gentilmente o leitor, a distinção que fazemos entre as 'sílabas de solmização' e as 'notas musicais': as primeiras vêm grafadas em itálico e letra minúscula, e as demais, em tipo corrente e letra maiúscula.
} 
PORTO, Delphim Rezende. A Arte da improvisação musical ao teclado no Renascimento italiano: a didática do contraponto segundo Girolamo Diruta (1610). Per Musi. Ed. por Fausto Borém, Eduardo Rosse e Débora Borburema. Belo Horizonte: UFMG, n.33, p.79-96.

conforme Antonio FERNANDEZ (1626, fl.43), a natureza matemática dos tons e semitons dentro da oitava varia de tamanho e, para o mesmo intervalo musical, podemos encontrar medidas diferentes. Esse autor, por exemplo, demonstra que a medida do intervalo de terça menor ré-fá é menor que a mesma terça menor compreendida entre mi-sol. Naquele contexto especulativo, são consideradas, assim, duas terças menores - uma maior e outra menor.

Três intervalos são significativamente importantes para o contraponto e a teoria modal, conforme demonstra Diruta: a quarta e a quinta. 0 intervalo de quinta, Diapente, ocorre em quatro espécies e, o de quarta, Diatessaron, em três.

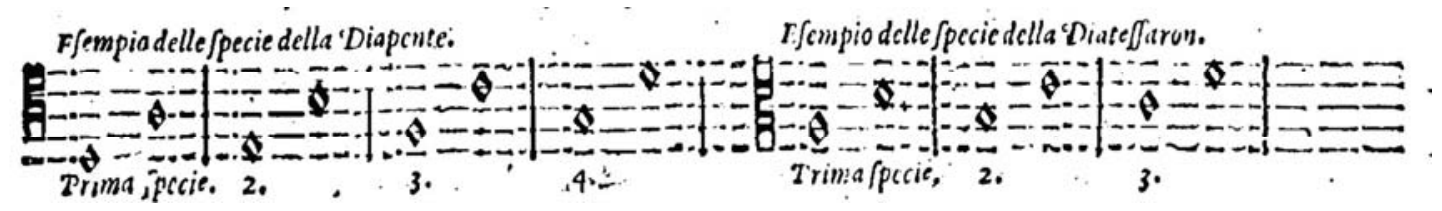

Figura 2: As quatro espécies de Diapente e as três espécies de Diatessaron que compõem a escala musical segundo Il Transilvano (p.268) ${ }^{6}$

A oitava ou Diapason, para estes teóricos, combina as diferentes disposições da Diapente com a Diatessaron e se manifesta em sete espécies, todas elas de, aproximadamente, cinco tons e um semitom, distribuídos diferentemente. Essas diferentes qualidades sonoras do mesmo intervalo, para ARTUSI $(1585$, fl.6), também funcionam como a matéria básica para a composição das regras do contraponto. 0 movimento entre os sons, enquanto preceptiva comum do antigo contraponto, considera, a priori, a natureza dos diferentes intervalos para determinar o desenvolvimento da polifonia. A educação do ouvido para a percepção destas regras, tópica recorrente em todos os tratados que consultamos, se baseia na diferenciação daquilo que é ou não correto enquanto movimento contrapontístico. Uma vez que essas regras advêm, para estes tratadistas, da natureza percebida e comprovada pela música especulativa, matemática, obedecê-las garante ao músico a segura indústria do belo.

\footnotetext{
${ }^{6}$ Os exemplos reproduzidos do tratado Il Transilvano aqui são fac-símile da edição de 1593 custodiada pela Biblioteca Internazionale della Musica di Bologna - a qual muito agradecemos - e gozam de nullaosta em nome do autor do presente artigo sob o protocolo 363/13.II.
} 
PORTO, Delphim Rezende. A Arte da improvisação musical ao teclado no Renascimento italiano: a didática do contraponto segundo Girolamo Diruta (1610). Per Musi. Ed. por Fausto Borém, Eduardo Rosse e Débora Borburema. Belo Horizonte: UFMG, n.33, p.79-96.

AARON no seu compendiolo (15??, fl.33), na Ottaua Regola sistematiza que o movimento entre as consonâncias deve considerar sempre caminhar para aquela mais próxima. Dessa forma, a terça menor deve ir ao uníssono; a terça maior, à quinta; a sexta menor deve descer à quinta e, a sexta maior, deve sempre ir à oitava. A décima menor vai à oitava e a maior à décima segunda. Como podemos ver, há um entendimento geral que os intervalos maiores tendem a se abrir e os menores, a fecharem-se. Além disso, é importante observar que estão contemplados nestes movimentos aqueles que fazem a cadência: a oitava e o uníssono. Para a cadência em oitava, se utiliza a sexta maior e para a cadência em uníssono, a terça menor impreterivelmente. Segundo a preceptiva de Gioseffo ZARLINO (1558, fl.21), a cadência está para a música tal como o ponto está para a prosa ou verso - com toda a sua consequência. 0 tratadista declara que exclusivamente no cantochão uma parte sozinha pode fazer cadência. A cadência em canto figurado envolve pelo menos duas partes e se divide em dois tipos: as que terminam em uníssono e as que terminam em oitava - chamadas cadências perfeitas. Outros autores consideram também como cadência as que se concluem com outras consonâncias, porém, para esse autor, devem ser nomeadas de 'imperfeitas'. Através da arte da diminuição, os compositores podem engenhosamente variar suas cadências e, nesse sentido, Diruta no livro II do segundo volume apresenta uma coletânea das mais "artificiosas e belas" das 320 cadências compostas por Gabriele Fattorini (floruit 1598-1609), para que o transilvano pudesse vislumbrar quão complexas e interessantes podem ser as mesmas.

Segundo Diruta, ao improvisar alla mente ou alla cartella, o músico deve observar o máximo possível as diversas regras sobre os movimentos entre as consonâncias justamente porque são elas que garantem beleza plena de uma composição. Dois tipos de movimentos melódicos são considerados no contraponto: o caminhar por grau conjunto e o saltar. Embora ambos os procedimentos sejam possíveis, os saltos requerem mais atenção, pois podem provocar diversos defeitos tanto melódicos quanto harmônicos. Do ponto de vista da harmonia das linhas melódicas, Diruta considera ainda dois artifícios: o moto contrario e o reto - o "oblíquo", o autor o inclui no contrario. Destes, considera como o mais belo, o contrário, pois conduz as vozes 
com "graça e variedade" e, segundo nosso autor (p.219), "dentre os movimentos, este é o mais difícil e, dele, depende tudo, de belo e de bom que há no contraponto estrito tão estimado pelos valent'huomini desta profissão".7

A este propósito, a primeira regra do contraponto prescrita pelo nosso autor é a que regula a relação entre as consonâncias perfeitas - oitava e quinta - justamente através do movimento contrário. Muito recomendado pelos tratadistas deste período, como Artusi e Aaron, este movimento deve ser empregado obrigatoriamente entre consonâncias do mesmo tipo a fim de garantir variedade à operação e evitar que haja a repetição das mesmas consonâncias ocultamente. 0 funcionamento do artifício é simples: enquanto uma voz ascender, a outra deve descender - tanto por salto quanto por grau conjunto. A sucessão de consonâncias perfeitas é considerada pouco elegante e, para a maior parte dos autores, um erro técnico. Das diversas alegações que explicitam, a mais distinta se refere ao vazio harmônico que o emprego de duas quintas ou duas oitavas em seguida traz à composição. A não observância do movimento contrário entre essas consonâncias gera implicitamente a repetição daquela última, como se pode ver no exemplo que Diruta nos oferece. As flechas por nós colocadas (Figura 3) indicam a nota que virtualmente existe dentro do intervalo, anotadas por extenso por Diruta. 0 movimento reto ou direto entre uma oitava e uma quinta e viceversa gera sempre este fenômeno e por isso deve ser empregado apenas entre consonâncias imperfeitas.

7 “...questo mouimento: ciò hò fatto, perche frà gli altri è il più difficile; e da questo depende tutto il buono, e'l bello del Contrapunto osseruato, tanto stimato da valent'huomeni di questa professione...". 

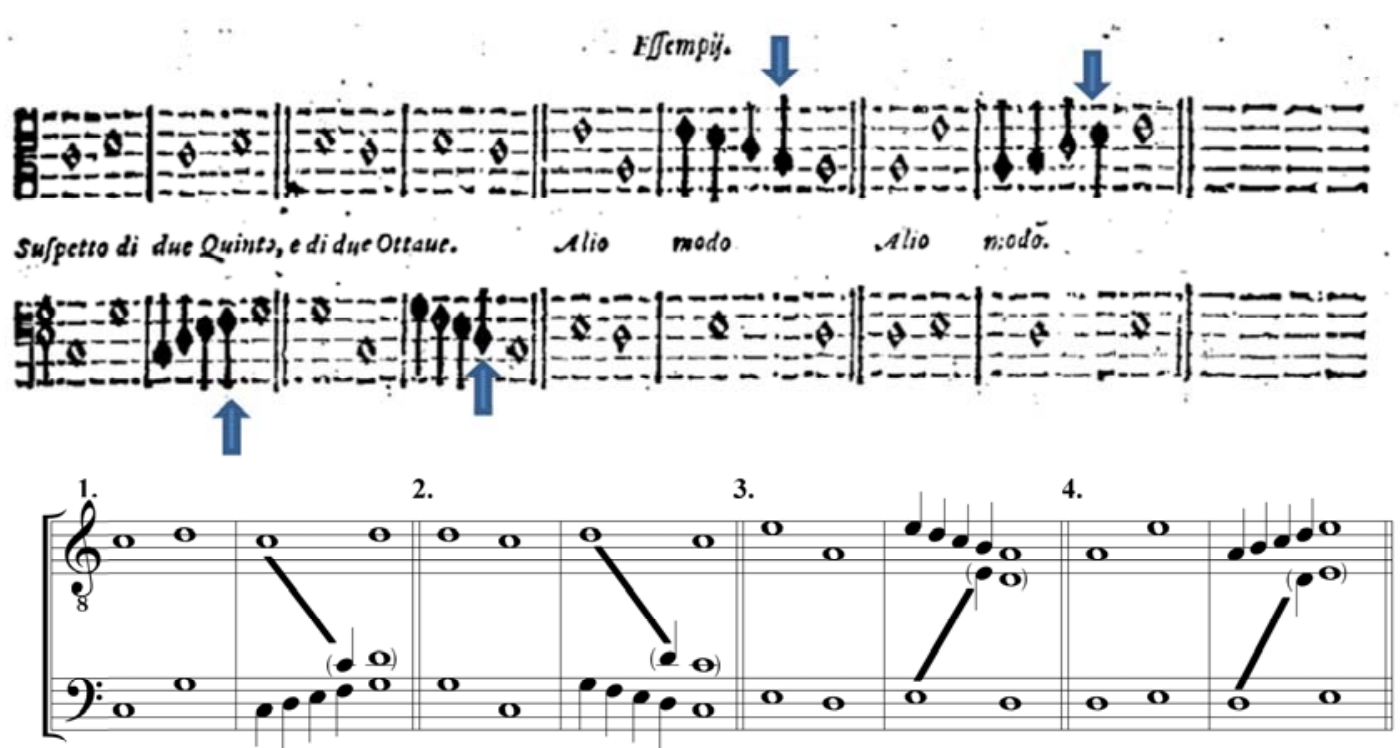

Figura 3: Il Transilvano (p.221) - Movimentos diretos entre consonâncias perfeitas que incorrem em quintas e oitavas paralelas ocultas (original e transcrição com notação moderna que com acréscimos e alterações para maior clareza).

No grupo de compassos número um da Figura 3, Diruta apresenta o movimento direto e ascendente entre uma oitava e uma quinta que resulta em uma quinta paralela oculta (Fá-Dó e Sol-Ré). A composição virtual dos intervalos musicais - coerente com a doutrina das espécies que vimos a pouco - é explicitada pelo autor através de semínimas que percorrem todo aquele âmbito e desvelam o paralelismo antes oculto. O segundo grupo de compassos descreve o movimento descendente entre uma quinta e uma oitava que ocasiona uma oitava paralela igualmente oculta (Ré-Ré e Dó-Dó). 0 terceiro e quarto grupos apresentam como resultado do movimento direto entre consonâncias perfeitas duas oitavas paralelas ocultas.

O segundo princípio sobre o contraponto estrito em Diruta coordena as terças e sextas entre si. Ele declara que entre consonâncias imperfeitas o movimento entre as mesmas deve ser livremente escolhido segundo o arbítrio do compositor/improvisador, mas recomenda combiná-las inteligentemente alternando as espécies de maior e menor, de modo que a sequência terça-sexta, considere fazer uma maior e outra menor. Igualmente livre deve ser, segundo a terceira regra, a ligação entre uma consonância perfeita e uma imperfeita. Na Figura 4, primeiro compasso, a sexta maior Sol-Mi vai à 
terça menor Ré-Fá por movimento direto; em seguida, a sexta maior Dó-Lá se fecha na terça menor Si-Ré; e, do mesmo modo, a sexta menor; Si-Sol se fecha na terça menor Lá-Dó. Apesar desta última demonstração não alternar as espécies maior e menor dos intervalos, ela segue a preceptiva de AARON (15??, p.6) de que um intervalo menor deve naturalmente se fechar ou descender.

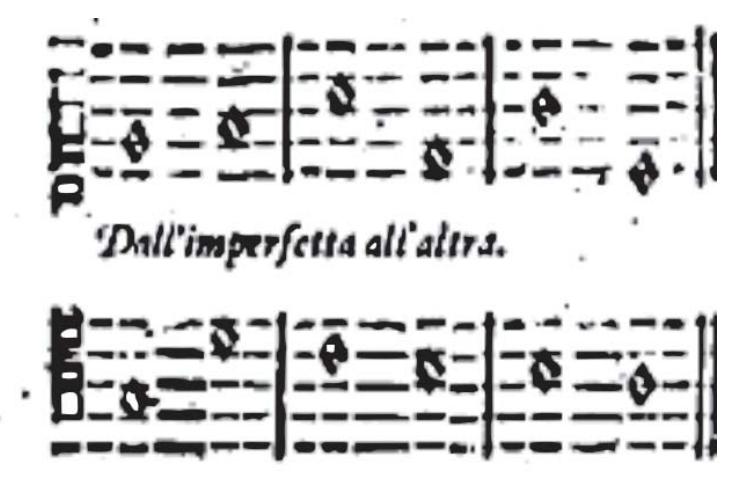

Figura 4: Il Transilvano (p.221) - Movimento direto entre consonâncias imperfeitas.

Como última observação sobre os movimentos entre as consonâncias, Diruta ensina ao transilvano o procedimento para, corretamente, aproximar uma consonância imperfeita de uma perfeita. Suma importância para o contraponto tem este artifício, pois é através deste que se realizam as cadências - como vimos acima, tanto em oitava quanto em uníssono - sempre através do moto contrario. De maneira geral, considerando a terça em relação às consonâncias perfeitas, podemos dizer que, como observa PACCHIONI (1995, p. 55), a maior é apta a ir à quinta e à oitava, e a menor, apenas ao uníssono. Da sexta, a maior é própria a andar à oitava e à quinta - caso uma voz fique parada e depois vá em terça - e a menor, pode se fechar em uma quinta, terça ou uníssono.

Não seria surpresa alguma se o nosso autor também expusesse, por extenso, as condições que sinalizamos acima. Contudo, através de uma regra geral - a do quarto movimento, moto contrario e semituono - Diruta simplifica essa relação. Ao estabelecer que uma das vozes cante as sílabas de solmização $m i$ - $f a$, um semitom, - Figura 5 - o autor garante o correto movimento entre as vozes sem precisar descrever o princípio da natureza dos intervalos. No primeiro e segundo compassos temos uma sexta maior 
que se abre à oitava - Sol-Mi/Fá-Fá, e, Fá-Ré/Mi-Mi, respectivamente. No terceiro compasso, seguindo a preceptiva, vemos que a sexta menor se fecha - neste caso, em uma quinta: Lá-Fá/Lá-Mi,

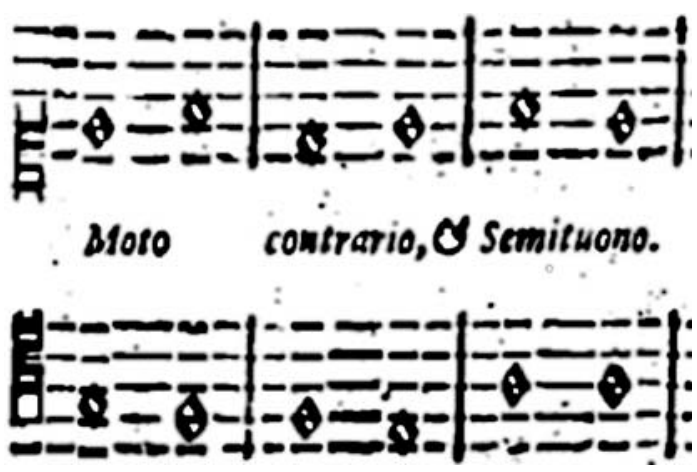

Figura 5: Il Transilvano (p.218) - Exemplo da preceptiva do Quarto movimento - contrário e semitom - entre consonâncias imperfeitas e perfeitas.

\begin{tabular}{|c|c|}
\hline Primo mouimento. & Primeiro movimento. \\
\hline $\begin{array}{c}\text { Dalla consonanza perfetta à dun'altra perfetta, si } \\
\text { và come il moto contrario. }\end{array}$ & $\begin{array}{l}\text { De uma consonância perfeita a outra perfeita, se } \\
\text { vai por movimento contrário. }\end{array}$ \\
\hline Secondo mouimento. & Segundo movimento. \\
\hline $\begin{array}{l}\text { Dalla consonanza imperfetta à dun'altra } \\
\text { imperfetta, si và come si vuole. }\end{array}$ & $\begin{array}{l}\text { De uma consonância imperfeita a outra } \\
\text { imperfeita, se caminha livremente. }\end{array}$ \\
\hline Terzo mouimento. & Terceiro movimento. \\
\hline $\begin{array}{c}\text { Dalla consonanza perfetta alla imperfetta, si va } \\
\text { come si vuole }\end{array}$ & $\begin{array}{l}\text { De uma consonância perfeita a uma imperfeita, se } \\
\text { vai livremente. }\end{array}$ \\
\hline Quarto mouimento. & Quarto movimento. \\
\hline $\begin{array}{c}\text { Dalla consonanza imperfetta alla perfetta, si và } \\
\text { con il moto contrario, e Semituono. }\end{array}$ & $\begin{array}{l}\text { De uma consonância imperfeita a uma perfeita, se } \\
\text { anda por movimento contrário e semitom. }\end{array}$ \\
\hline
\end{tabular}

Figura 6: Quadro sinótico (original e traduzido) dos movimentos contrapontísticos segundo Girolamo Diruta - Il Transilvano (p.217).

A variedade do contraponto está justamente baseada na observância destes movimentos preceituados e sinteticamente expostos na Figura 6 - principalmente daqueles relacionados às consonâncias perfeitas, que são, para Diruta, os movimentos mais difíceis. Para evitar enganos (e oitavas paralelas ou ocultas) o autor recomenda escrever entre as linhas o número dos intervalos que as consonâncias fazem - como se 
pode ver abaixo na Figura 7 - de nota contra nota sobre um soggeto. A utilização, na parte do tenor, de uma melodia em cantochão para a indústria do contraponto é muito significativa: sua importância na música seiscentista equivale à relevância da linha do Baixo para a harmonia oitocentista, e funciona como uma linha-guia sobre e sob a qual se desenvolvem outras melodias em canto figurado.

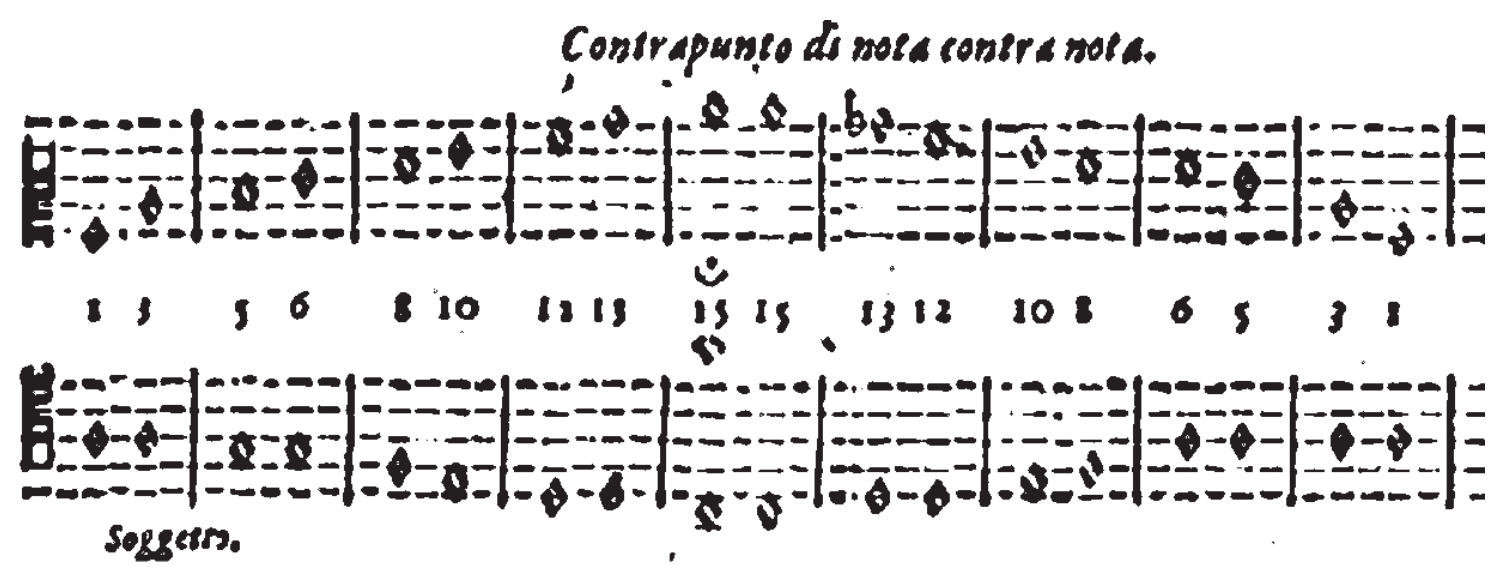

Figura 7: Il Transilvano (p.234) - Contraponto de nota contra nota. Os intervalos entre uma voz e outra devem ser grafados numericamente segundo Girolamo Diruta.

\section{3 - 0 método para "falar" de improviso}

Uma vez aprendidas as regras sobre os intervalos e seus movimentos, a estrada do ensino da arte do contraponto prossegue, conforme a instrução de Diruta, na fatura de contrapontos de obbligo - obrigações particulares que devem ser observadas - além, é claro, das regras já estabelecidas - sobre uma melodia em cantochão, o Tenor. Tal Tenor deve permanecer o mesmo durante o aprendizado para que o discípulo possa confrontar problemáticas diferentes em um mesmo contexto harmônico, seguindo o máximo possível todas as regras. Diruta apresenta alguns exercícios preparatórios antecedentes aos obblighi para que o Transilvano com o mesmo Tenor, que é neste caso, curto, experimente os procedimentos e tratamentos da dissonância e da rítmica contrapontística. 
O primeiro tipo de exercício previsto por Diruta é o de 'nota contra nota' - uma espécie de contraponto em cantochão e em ritmo simples, que se desenvolve apenas em consonâncias. Além de obrigar o estudante a realizar os movimentos entre as várias consonâncias corretamente, este exercício tem por finalidade primeira a educação do ouvido - talvez o aprendizado mais complexo do processo, tendo em vista, principalmente, o desenvolvimento do contraponto alla mente, base para a improvisação. Mesmo escolásticos, os exercícios já preveem a realização de cadências obedecendo a preceptiva de G. Zarlino - tanto na figura 7 quanto na 8, da terça menor indo ao uníssono. 0 segundo tipo de exercício preceituado pelo nosso autor contempla o contraponto com figuras de mesmo valor - duas notas contra uma - e o terceiro e quarto tipos, em síncopas. O quinto e último tipo de contraponto preparatório deve ser realizado em figuração rápida. Tal preparação e disposição, semelhantes àquela registrada por Johann Fux (1660-1741) mais de um século depois, serão estabelecidas sob o nome de espécies. Segue abaixo o primeiro exercício (Figura 8) com a indicação dos movimentos intervalares.

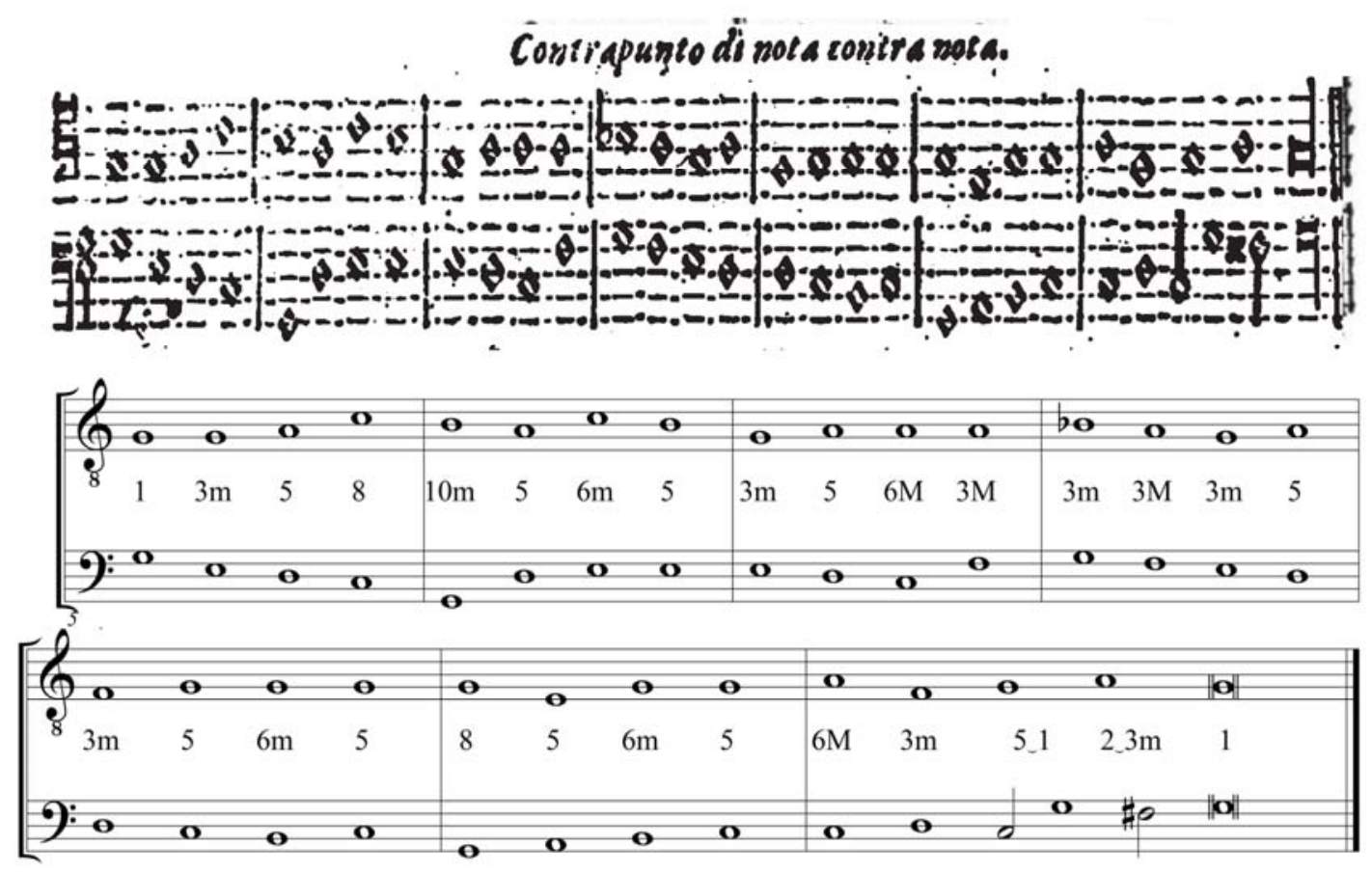

Figura 8: Anotações do Contraponto de nota contra nota do Il Transilvano (p.237; original e transcrição para claves hodiernas com intervalos entre as pautas). 
PORTO, Delphim Rezende. A Arte da improvisação musical ao teclado no Renascimento italiano: a didática do contraponto segundo Girolamo Diruta (1610). Per Musi. Ed. por Fausto Borém, Eduardo Rosse e Débora Borburema. Belo Horizonte: UFMG, n.33, p.79-96.

Após aprender a manipular os sons corretamente, Diruta prevê a adequação desse material sonoro a determinadas representações das emoções e assuntos por meio dos diversos modos ou tons - que, naquela preceptiva, são o conteúdo extrínseco dessa linguagem: as paixões e os assuntos que a música descreve. Segundo antigo uso, os tons, assim como na linguagem falada, são a codificação da expressão humana - o decoro basilar da música. Assim como o orador usa certas inflexões e entonações para dar sentido e coerência ao conteúdo que profere tendo em vista a natureza do que descreve e o fim do seu discurso, igualmente considera, o nosso autor, os modos para a música. Consequência das diferenças entre as disposições das espécies da Diatessaron combinadas com a Diapente, os modos se servem das várias espécies da Diapason para instituir doze tipos de escalas: seis autênticas e seis plagais. - baseadas nas antigas seis sílabas (ou notas de solmização) daquela música: ut ,re , mi, fa, sol e la. 0 primeiro e segundo tons se baseiam na nota $r e$, o terceiro e quarto, na nota $m i$, o quinto e o sexto, na nota $f a$, o sétimo e o oitavo, na nota sol, o nono e o décimo, na nota $l a$, e o décimo primeiro e décimo segundo, na nota $u t$. Diruta explica que a diferença musical entre uma escala autêntica e uma plagal está no tipo de escrita que comporta. A autêntica modula normalmente figurações ascendentes e a plagal, descendentes e, embora a última se componha do mesmo material da primeira e cadencie nas mesmas cordas (notas), comporta paixões distintas daquela.

Além de determinar o tipo de afeto de uma composição, o modo prevê, sob o paradigma vocal, o âmbito que se deve situar as melodias, seus limites ao agudo e ao grave e o lugar ordinário de se fazer as cadências - no primeiro, quinto e terceiro graus do modo autêntico, que neste caso, empresta suas cordas cadenciais ao plagal. A discussão sobre o modalismo é recorrente em vários tratados do período, como no Melopeo de Pietro Cerone (1566-1625) publicado em 1613. Durante séculos o cantochão se declarou sob apenas oito modos, porém, conforme demonstrado por Zarlino e Glareanus, o âmbito e as espécies que muitos destes modulavam já constituíam outros tons. Assim, não se deveria considerar que tais autores estivessem criando novos modos, mas, sim, codificando um uso que já existia. 
PORTO, Delphim Rezende. A Arte da improvisação musical ao teclado no Renascimento italiano: a didática do contraponto segundo Girolamo Diruta (1610). Per Musi. Ed. por Fausto Borém, Eduardo Rosse e Débora Borburema. Belo Horizonte: UFMG, n.33, p.79-96.

A despeito dessa controvérsia, certo é que muitos compositores para teclado, entre eles Andrea Gabrieli (1532/3-1585), Claudio Merulo (1533-1604) e Adriano Banchieri (1568-1634), realizaram considerável número de obras em que os doze tons são exercitados. Tal produção corresponde à demanda que o antigo organista tinha de entoar, durante os diversos atos litúrgicos, as notas do coro e de improvisar, em canto figurado, sobre os cantochãos. O quarto livro do segundo volume do Il Transilvano se dedica justamente a expor as diferenças dos modos "modernos" e aqueles eclesiásticos a fim de propiciar ao tecladista uma correta base tonal para a entoação. Segundo nosso autor, muitos compositores de canto figurado, por não conhecerem a correta disposição dos vários tons, confundem as suas espécies e modulam indecorosamente os assuntos sob o modo equivocado, deixando de lado os efeitos naturais que cada escala representa.

Além da imitação correta do ponto de vista dos tons e do seu âmbito coral - uma vez que os modos deviam ser concordes à problemática vocal e muitas vezes ocorriam transpostos - Diruta determina que o decoro do modo seja compreendido também enquanto timbre, ao órgão. Para cada tom o organista deve escolher dentre os diversos registros do instrumento aqueles mais convenientes ao efeito natural que se credita aos diferentes tons. Dessa maneira, o conhecimento dos diversos tons deveria refletir tanto o decoro das cadências corretamente realizadas nas cordas (notas) particulares de cada modo quanto uma determinada sonoridade dos tubos.

A cadência é considerada, neste contexto, como o meio mais seguro para a expressão de um modo em canto figurado. Uma composição musical só conseguiria expressar-se correta e decorosamente se observasse, na parte do Tenor, principalmente, as cadências regulares do modo que é mais adequado ao seu assunto. Igualmente, para Diruta, o soggetto da música, tema da imitação - também chamado de fuga - deveria considerar modular, no caso de um modo autêntico, suas notas ascendentemente, ou se plagal, descendentemente. Para exemplificar este uso, nosso autor, no livro III do segundo volume, apresenta diversos Ricercari - a forma das formas do séc. XVI - de vários compositores que assim procederam. 
Na Figura 9 temos a demonstração que nosso autor faz das cordas (notas) cadenciais de cada tom, segundo a sua natureza autêntica ou plagal. Observe que Diruta não coloca os acidentes necessários para o artificio da cadência: é provável que pressuponha que tenha sido claro na preceptiva do semitom mi-fa nas cadências, conforme já vimos anteriormente. ${ }^{8}$

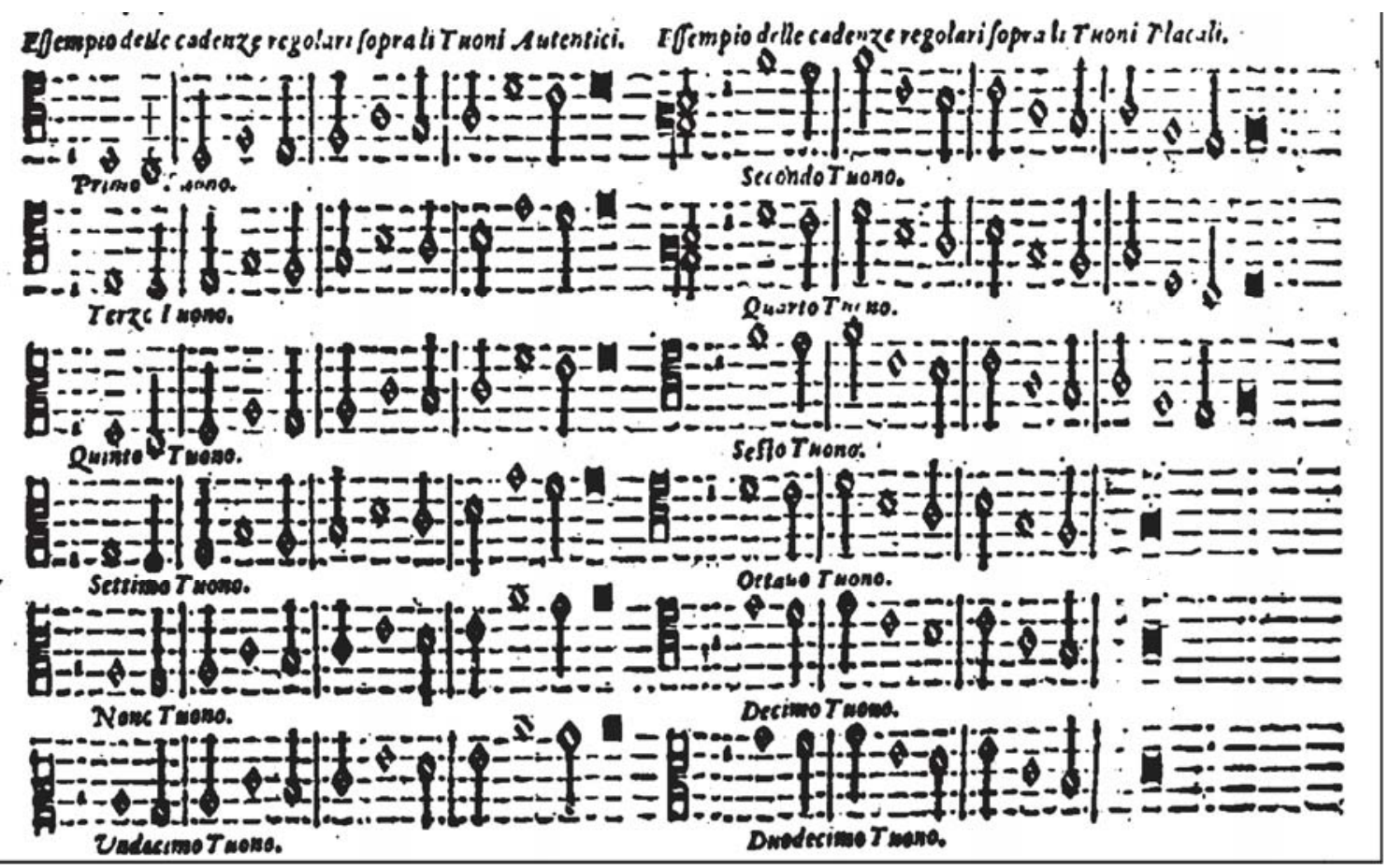

Figura 9: Il Transilvano (p.276) - Tabela sinótica das cordas (notas) cadenciais dos modos autênticos e plagais.

\section{Considerações finais}

Como forma contrapontística de imitação condensada, a prática da improvisação e da composição a vozes e sobre os modos, constitui o verdadeiro exercício da arte da música para Diruta. Tal índice são as peças de repertório que o autor apresenta ao transilvano ao final das explicações sobre o contraponto e os modos: diversas Toccate ao final do primeiro volume, Ricercari em todos os doze tons no livro II e as muitas

\footnotetext{
${ }^{8}$ Para aprofundamento do assunto da solmização e consequente leitura de partituras renascentistas, ver DOMINGOS, Nathalia. Tradução comentada da primeira parte do tratado A plaine and easie introduction to praticall musicke (1597) de Thomas Morley. 2012. 353p. Dissertação (Mestrado) - Escola de Comunicações e Artes, Universidade de São Paulo, São Paulo.
} 
PORTO, Delphim Rezende. A Arte da improvisação musical ao teclado no Renascimento italiano: a didática do contraponto segundo Girolamo Diruta (1610). Per Musi. Ed. por Fausto Borém, Eduardo Rosse e Débora Borburema. Belo Horizonte: UFMG, n.33, p.79-96.

Intonazioni do livro IV9. Tais obras encerram em si, por extenso, sobretudo habilidades requeridas ao prático do órgão e dos teclados - como imitar, por exemplo, no caso do organista que acompanha um coro, improvisadamente, os temas cantados ou mesmo realizar uma introdução em canto figurado aos cantochãos da liturgia com os elementos da melodia que será entoada. No Il Transilvano temos uma ótima introdução que situa esse assunto dentro do panorama da formação do organista e das obras que aprofundam o tema. Métier da atuação profissional daqueles músicos e método didático da arte, o contraponto - aliado ao conhecimento técnico do instrumento - é, naquele momento histórico, gramática da língua musical: parâmetro que regula a modulação dos sons - ou como define ZACCONI (1622, p.5): "caminho seguro e sólido que conduz ao prazer e ao bom gosto aqueles que amam a música".

\section{Referências}

1. AARON, Pietro (15xx). Compendiolo di molti dubbi. Fac-símile - Milão. Bologna: Forni Editore, s/d.

2. ARTUSI, Giovanni Maria (1585). L'arte del Contraponto. Fac-símile - Veneza. Bologna: Forni Editore, 1980.

3. BANCHIERI, Adriano (1605). L'organo suonarino. Fac-símile - Bolonha. Bologna: Forni Editore, s/d.

4. CERONE, P. (1613). El Melopeu. Mvsica Theorica y pratica. Fac-símile - Nápoles. Disponível em < http://imslp.org/wiki/El_melopeo_y_maestro_(Cerone,_Pietro) >. Acesso em: 10 Set 2014.

5. EXÍMENO, Antonio (1774). Del origen y reglas de la musica, con la historia de su progresso, decadência y restauracion. Fac-símile - Madri. Madrid: Maxtor Editorial, 2010.

6. DIRUTA, Girolamo (1593 e 1610). Il transilvano dialogo sopra il vero modo di sonar organi, et istromenti da pena. Fac-símile -Veneza. Bologna: Forni Editore, s/d.

\footnotetext{
${ }_{9}^{9}$ Para a prática do dedilhado e da arte das diminuições Diruta considera a Toccata como o gênero mais favorável, enquanto que o Ricercare, forma mais estrita e politemática, é o gênero mais artificioso para a prática da composição. Já as Entoações ou Intonazioni são peças curtas em canto figurado que antecedem o cantochão ou outra melodia executada pelo coro durante a liturgia e funcionam como espécie de introdução que dá o tom e improvisa alguma imitação sobre o soggetto daquela antífona ou hino. Deste gênero, muito difusas são as publicações de Andrea e Giovanni Gabrielli sob os dozes tons em tablatura em 1593.
} 
PORTO, Delphim Rezende. A Arte da improvisação musical ao teclado no Renascimento italiano: a didática do contraponto segundo Girolamo Diruta (1610). Per Musi. Ed. por Fausto Borém, Eduardo Rosse e Débora Borburema. Belo Horizonte: UFMG, n.33, p.79-96.

7. FERNANDEZ, António (1626). Arte de Musica de Canto Dorgam e Canto Cham e Proporçoēs de Musica divididas harmonicamente. Lisboa: Pedro Craesbeeck.

8. PACCHIONI, Giorgio (1995). Selva di varii precetti: La pratica musicale tra i secoli XVI e XVIII nelle fonti dell'epoca. Bologna: Orpheus Edizioni.

9. REZENDE PORTO, Delphim (2013). Girolamo Diruta: II Transilvano - Diálogo sobre a maneira correta de tocar órgão e instrumentos de teclado. Um estudo sistemático do Tratado e da Música em princípios do séc. XVII. 2013. 342f. Dissertação (Mestrado) - Escola de Comunicações e Artes, Universidade de São Paulo, São Paulo.

10. ZACCONI, Ludovico (1592 e 1619). Prattica di Musica I e II. Fac-símile - Veneza. Bologna: Forni Editore, s/d.

11. ZARLINO, Gioseffo (1558). Le istitutione harmoniche. Fac-símile - Veneza. Bologna: Forni Editore, 2008.

\section{Literatura recomendada}

1. DOMINGOS, Nathalia (2012). Tradução comentada da primeira parte do tratado A plaine and easie introduction to praticall musicke (1597) de Thomas Morley. 353p. Dissertação (Mestrado) - Escola de Comunicações e Artes, Universidade de São Paulo, São Paulo.

Notas sobre o autor

Delphim Rezende Porto é organista, cravista e regente. Iniciou seus estudos de piano moderno aos sete anos com a polonesa Donata Lange, na Universidade Livre de Música, em São Paulo, e é Mestre e Doutorando em Musicologia pela ECA-USP, sob a orientação

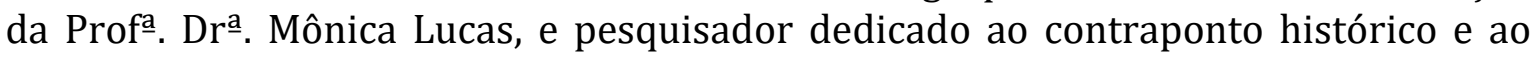
canto figurado seiscentista italiano. Aperfeiçoa-se aos teclados históricos do cravo, órgão e clavicórdio com Nicolau de Figueiredo, Elisa Freixo e Peter Sykes. Licenciado pleno em Pedagogia pela PUC-SP, graduou-se como compositor e regente pelo Instituto de Artes da UNESP, onde também atuou como cravista da sua Orquestra Acadêmica. Durante o ano de 2016, a convite da Columbia University de Nova Iorque e financiamento BEPE/FAPESP processo 2015/22613-0, realiza pesquisa musicológica para seu doutoramento sob a orientação do Prof. Dr. Giuseppe Gerbino. 